\title{
Especialidades Médicas - Cirurgia Cardiovascular
}

\author{
Paulo Manuel Pêgo Fernandes
}

Apesar do gosto pelo estudo, nenhuma matéria havia me despertado interesse de aprofundamento maior, até o contato com a disciplina de Laboratório em Biologia ministrada durante a segunda série do antigo curso colegial. Essa Disciplina correspondia à parte prática do curso de Biologia, que nesse ano tratava do estudo da Zoologia.

Essa matéria efetivamente me fascinou, a ponto de freqüentar aulas de outras turmas. No segundo semestre desta série, através de convênio do Colégio Arquidiocesano com o Instituto de Biologia Marinha da Universidade de São Paulo, os alunos que mais se destacaram, puderam realizar um estágio supervisionado. Esse acesso ao Laboratório do Colégio e o estágio foram essenciais na minha decisão de ser Médico.

No terceiro Colegial, seguro quanto à escolha pela carreira médica, preparei-me para os exames vestibulares no Colégio Objetivo. Felizmente fui bem sucedido nos exames, podendo escolher cursar a Faculdade de Medicina da Universidade de São Paulo (FMUSP). Inesperadamente, recebi um telefonema parabenizando-me pelo sucesso nesses exames de uma ex-professora do curso primário, que acompanhava, à distância, o desempenho de seus ex-alunos. A sra. Sonia Tariki convidou-me a ir à sua casa para que pudéssemos nos rever e conversar. Nessa conversa, acabei, fortuitamente, conhecendo o seu irmão, o Dr. José Tariki, Médico formado pela Universidade de São Paulo, e naquela ocasião Médico Residente de Cirurgia Plástica. Comentei a vontade de tornar-me cirurgião e que adorava estudos anatômicos e de dissecção. Por meio de suas orientações e apresentações, engajei-me no início do segundo ano da Faculdade de Medicina em um grupo de cirurgia experimental e de pesquisas comandado pelo Prof. Noedir Stolf. Foi fascinante ter acesso aos transplantes de coração em cães e às atividades da Cirurgia Torácica e Cardiovascular em humanos. Foi um período especialmente estimulante em que trilhei todos os passos do campo operatório: desde a função de anestesista dos cães, passando por instrumentador, auxiliar e cirurgião. Foi de valia inestimável o acesso à parte prática das operações e às pesquisas científicas, pelas quais desenvolvi gosto e familiaridade. Já nessa época tive despertado também o prazer pela docência, graças à oportunidade de ensinar aos alunos mais jovens que se engajaram no grupo. O desenvolvimento dessas atividades fez com que o próprio curso de medicina se tornasse ainda mais atrativo, uma vez que eu podia aplicar, na prática, muitos dos ensinamentos teóricos aprendidos nas aulas.

A Residência de Cirurgia Geral, realizada no Hospital das Clínicas, foi uma boa oportunidade de conhecer com maior profundidade outras áreas da cirurgia. Estava, porém, impaciente para o início da Residência de Cirurgia Cardíaca no Instituto do Coração do Hospital das Clínicas da FMUSP (InCor).

No InCor pude aprofundar a convivência com vários colegas com quem mantinha contato esporádico através da minha atuação na Divisão de Cirurgia Experimental e em pesquisas com pacientes. A Residência de Cirurgia Cardíaca foi fundamental em minha formação. A oportunidade de acesso a operações diversas, realizadas por cirurgiões altamente competentes, foi muito enriquecedora. Acredito que o residente de cirurgia cardíaca do InCor, que efe-

Professor livre-docente e associado do Departamento de Cárdio-Pneumologia da FMUSP. 
tivamente se dedique ao aprendizado, acumula um ótimo embasamento ao final desse período. Esse embasamento compreende principalmente atividades cirúrgicas, de terapia intensiva, participação de trabalhos científicos com divulgação em Congressos da área.

Após a Residência, fui indicado para o cargo de Médico Preceptor, permanecendo nesta função por dois anos. Além do meu treinamento em cirurgia cardíaca, tive a oportunidade de participar do ensino dos residentes tanto na atuação prática quanto teórica. Ao longo desse período, trabalhei para o aprimoramento da parte teórica da Residência, e do estímulo ao estudo através de Seminários.

Ao final da Preceptoria, iniciei o Curso de Pós-Graduação, fazendo parte da primeira turma de doutoramento da recém criada Área de Concentração em Cirurgia Torácica e Cardiovascular. A Pós-Graduação, na época em que a cursei, apresentava como exigências um grande número de créditos em Disciplinas e em atividades didáticas com os alunos da FMUSP. Certamente exigia uma grande dedicação, praticamente em período integral por dois anos.

Esta dedicação, muitas vezes é incompatível com a necessidade de trabalho nesta fase da vida. Para isso, foi criada pelo Prof. Adib Jatene, uma Bolsa que se aproximava do salário do Médico Assistente. Atualmente, ocorreram várias modificações a fim de permitir que médicos formados há mais tempo, com diversas atribuições tenham condições de realizar o Doutoramento na Faculdade. Certamente o acesso tornou-se mais democrático, com reflexos no ensino que esses novos Doutores levarão a muitas Faculdades.

Fui indicado pelo Prof. Adib Jatene para chefiar o Serviço de Cirurgia Cardíaca em Taubaté. Lá, coordenei a montagem de um Serviço com Hemodinâmica, Unidade de Terapia Intensiva Cardiológica, Serviço de Métodos Gráficos e Ambulatório de Cardiologia e Cirurgia Cardíaca, além de Sala Operatória específica para cirurgia cardíaca a partir de 1992. Coordenei essas Unidades e chefiei o Serviço de Cirurgia Cardíaca durante três anos, onde foram operados centenas de pacientes com bons resultados. A Santa Casa, porém, começou a apresentar grandes dificuldades financeiras, comprometendo a qualidade de nosso trabalho o que nos obrigou a interromper tal projeto. O nosso retorno para o InCor foi facilitado pelos inúmeros amigos da Instituição. Quando da abertura de uma vaga de Médico Assistente do Serviço de Cirurgia Torácica, através de Concurso com provas escrita, oral e títulos, fui aprovado, sendo posteriormente efetivado como Médico Assistente da Divisão Cirúrgica do InCor. Em 1997 defendi a Tese de Doutoramento e em 1999 realizei o concurso de Livre-Docência que constou de prova teórica, prova prática, defesa de títulos e defesa de Tese.

Nos últimos anos tenho exercido atividades como Cirurgião de Tórax e Cardiovascular no InCor, com atividades tanto Assistenciais como de Pesquisa. $\mathrm{Na}$ área de assistência, tenho coordenado a área cirúrgica do Transplante Pulmonar que felizmente tem crescido em quantidade e qualidade ao longo dos últimos anos. Na área de Ensino, participo ativamente no curso de graduação e na Coordenação da Liga de Cirurgia Torácica e Cardiovascular, que tem como orientador o Prof. Fabio Jatene; na pós-graduação atualmente sou o Coordenador Substituto do Programa de Cirurgia Torácica e Cardiovascular.

Essa tríplice atividade embora desgastante obriga-nos a manter uma atualização constante nessas subespecialidades, fato que se reflete em minhas participações e apresentações de trabalhos em Congressos das áreas de coração e pulmão, assim como pelas publicações também nas duas áreas. Atualmente coordeno o Serviço de Apoio a Pesquisa Experimental do InCor.

Em paralelo a atividade acadêmica, a área proporciona a possibilidade de atuação em diversos hospitais em São Paulo e no Brasil. Nessas atividades é fundamental o trabalho em equipe, pois desta equipe depende o resultado e a viabilidade das operações, por se tratarem, na maioria das vezes, de operações de grande porte. Em especial para o recém-formado é praticamente obrigatório o engajamento numa equipe já constituída no intuito de aprimorar a formação e de viabilizar o trabalho. Acredito, como em qualquer área de atuação, que o trabalho e a dedicação abrem portas para que as pessoas atinjam a realização profissional. 